\title{
Mediators of Inflammation - A Potential Source of Biomarkers in Oral Squamous Cell Carcinoma
}

\author{
Mircea Tampa, ${ }^{1,2}$ Madalina Irina Mitran, ${ }^{1,2}$ Cristina Iulia Mitran $\mathbb{D D}^{1,2}$ \\ Maria Isabela Sarbu $\mathbb{D}^{2},{ }^{2}$ Clara Matei, ${ }^{2}$ Ilinca Nicolae, ${ }^{1}$ Ana Caruntu $\left(\mathbb{D},{ }^{3}\right.$ \\ Sandra Milena Tocut, ${ }^{4}$ Mircea Ioan Popa, ${ }^{2,5}$ Constantin Caruntu $\mathbb{D}^{2,6}$ \\ and Simona Roxana Georgescu ${ }^{1,2}$ \\ 1 "Victor Babes" Clinical Hospital for Infectious Diseases, 281 Mihai Bravu, 030303 Bucharest, Romania \\ 2"Carol Davila” University of Medicine and Pharmacy, 37 Dionisie Lupu, 020021 Bucharest, Romania \\ 3"Carol Davila” Central Military Emergency Hospital, 134 Calea Plevnei, 010825 Bucharest, Romania \\ 4 "Wolfson Medical Center", 61 Halochamim Street, 58100 Holon, Israel \\ 5 "Cantacuzino" National Medico-Military Institute for Research and Development, 103 Splaiul Independentei, \\ 050096 Bucharest, Romania \\ “"Prof. N. Paulescu” National Institute of Diabetes, Nutrition and Metabolic Diseases, 22-24 Gr. Manolescu, \\ Bucharest 011233, Romania \\ Correspondence should be addressed to Constantin Caruntu; costin.caruntu@gmail.com
}

Received 11 July 2018; Accepted 25 October 2018; Published 12 November 2018

Academic Editor: Nejat K. Egilmez

Copyright ( 2018 Mircea Tampa et al. This is an open access article distributed under the Creative Commons Attribution License, which permits unrestricted use, distribution, and reproduction in any medium, provided the original work is properly cited.

Oral squamous cell carcinoma (OSCC) is the most common tumour of the oral cavity, associated with significant morbidity and mortality. It is a multifactorial condition, both genetic and environmental factors being involved in its development and progression. Its pathogenesis is not fully elucidated, but a pivotal role has been attributed to inflammation, strong evidence supporting the association between chronic inflammation and carcinogenesis. Moreover, an increasing number of studies have investigated the role of different mediators of inflammation in the early detection of OSCC. In this review, we have summarized the main markers of inflammation that could be useful in diagnosis and shed some light in OSCC pathogenesis.

\section{Introduction}

Oral cancer accounts for about $4 \%$ of all cancers. Histologically, over $90 \%$ of cases are diagnosed as oral squamous cell carcinoma (OSCC) [1]. OSCC is a destructive malignant tumour with an invasive behaviour and significant risk of metastases [2]. The most common localization is the tongue, but other frequent sites for tumour formation are the lips and floor of the mouth $[3,4]$. OSCC is particularly diagnosed in the elderly, and although its pathogenesis is not fully understood, the main risk factors postulated include smoking, alcohol use, exposure to radiation and chemical carcinogens, infections, and immunosuppression [5-7]. With respect to infectious agents, a recent meta-analysis has shown that the human papillomavirus (HPV) genome is present in approximately one third of OSCC samples, HPV types 16 and 18 being the most commonly detected [8]. The most frequent premalignant lesions which can progress to OSCC are oral leukoplakia (OLK), oral lichen planus (OLP), and erythroplasia [5, 9]. A surgical approach of the tumour is the mainstay of treatment, but new therapies such as photodynamic therapy are promising, particularly in early-stage OSCC $[10,11]$.

The process of malignant transformation is complex and incompletely elucidated $[12,13]$. The role of inflammation in carcinogenesis was first suggested by Rudolf Virchow in 1963 [14]. Since then, various studies have shown that chronic inflammation is a pathological response that can act to the detriment of the host and influences cell homeostasis and 
various metabolic processes, inducing changes even at the genomic level, which can promote carcinogenesis [15]. Moreover, several studies have suggested a pivotal role of chronic inflammation in carcinogenesis through the modulation of proinflammatory cells and cytokine production $[12,16]$. In this review, we summarize the main mediators of inflammation that might be involved in the pathogenesis of OSCC and could represent biomarkers for the early diagnosis of the tumour.

\section{Tumour Inflammatory Cell Infiltrate}

The cells of the inflammatory infiltrate along with the mediators they release play an essential role in the formation of a suitable microenvironment that allows an uncontrolled cell proliferation $[17,18]$. Two pathways of inflammation involved in the promotion of carcinogenesis, namely, the intrinsic pathway mediated by tumour cells and the extrinsic pathway mediated by tumour-infiltrating immune cells, have been described [19]. The tumour environment is an important entity, including both immature and adaptive immune cells; among them, the main role is played by tumourassociated macrophages (TAMs) and T lymphocytes. TAMs correlate with tumour progression, their presence in the inflammatory infiltrate being an unfavourable prognostic factor and represent an important source of cytokines [20]. Macrophages have the ability to release numerous enzymes and mediators which interfere with angiogenesis, cell proliferation, and metastasis. For example matrix metalloproteinases lyse the extracellular matrix and subsequently promote metastasis, and growth factors (epidermal growth factor (EGF), vascular endothelial growth factor (VEGF), fibroblast growth factor (FGF), etc.) favour cell proliferation $[19,21]$.

T lymphocytes can exert both inhibitory and stimulating effects on carcinogenesis through the cytokines they release; interleukin- (IL-) 6, IL-17, and IL-23 have a proinflammatory effect, favouring tumour progression, IL-12 and interferongamma (IFN- $\gamma$ ) exhibit an antitumour effect and tumour necrosis factor alpha (TNF- $\alpha$ ), transforming growth factor beta (TGF- $\beta$ ), and IL- 6 exert direct action on cell survival [20]. The development of a proinflammatory environment will enhance the interaction between tumour cells and their stromal cells that will underlie the initiation of carcinogenesis $[22,23]$. Kullage et al. analysed the inflammatory infiltrate in OSCC and observed that lymphocytes represent the most abundant cell population. However, in poorly differentiated OSCC, the infiltrate was scarce. Therefore, they noticed a correlation between the infiltrate size and cell differentiation. This can be the result of the immunosuppression generated by malignant cells [24]. Malignant cells promote the migration of immunosuppressive cells into the tumour microenvironment resulting in the inhibition of immune response. The main recruited cells are regulatory $\mathrm{T}$ cells [25]. Thus, an increased number of lymphocytes in the inflammatory infiltrate is associated with a better prognosis while a decreased number of lymphocytes is associated with a lower survival rate. Other unfavourable prognostic factors include smoking, poorly differentiated tumours, and tumour localization (tongue) [26].
In order to establish the role of the inflammatory infiltrate, Mashhadiabbas analysed 125 samples from patients diagnosed with dysplasia (mild, moderate or severe) or OSCC, and found a positive correlation between the intensity of inflammatory infiltrate and lesion severity. The most abundant inflammatory infiltrate was observed among OSCC patients [27]. Lo Muzio et al. also studied the inflammatory infiltrate that accompanies OSCC and noticed a dense inflammatory infiltrate in well- and moderately differentiated tumours. In contrast, in the case of poorly differentiated tumours, a small amount of inflammatory infiltrate was revealed [28].

The study by Pellicioli et al. found an increased level of CD8 lymphocytes in OSCC compared to dysplastic lesions. In addition, they found a lower number of mature dendritic cells and an increased number of immature dendritic cells in OSCC samples compared to oral epithelial dysplasia (OED), a fact that might be involved in carcinogenesis [29]. Furthermore, Fang et al. have shown that the increased expression of CD8 lymphocytes in inflammatory infiltrate in OSCC specimens may be seen as a favourable predictor of survival. However, they have noticed that CD57 expression is a better survival marker than CD8 and CD4 [30].

Numerous studies have established the role of mast cells in allergies and inflammation, but recent research has shown that mast cells are also involved in angiogenesis and carcinogenesis [31]. Their role in tumour development and progression is debatable given that in some cancers, mast cell infiltration was correlated with a good prognosis but in others with an unfavourable outcome [32]. The role of mast cells in carcinogenesis is supported by the release of numerous cytokines, chemokines, and angiogenic factors [33-35]. Histamine, heparin, and FGF are among the most important mediators involved in angiogenesis [36].

The study by Kabiraj et al. revealed a positive correlation between mast cell infiltration and microvessel density in OSCC samples, suggesting the possible role of mast cells in tumour angiogenesis [37]. In contrast, the study by Kalra et al. showed a decrease in mast cell infiltration and an increase in the number of blood vessels from well-differentiated to poorly differentiated OSCC and concluded that mast cells are not the main regulators of tumour angiogenesis [36]. However, the study by Jain et al. highlighted that the presence of a high amount of mast cells and eosinophils in the tumour microenvironment is associated with a good prognosis in OSCC [38].

\section{Markers of Inflammation in OSCC}

To date, there are no reliable biomarkers for the detection of malignant transformation in early stages. In this sense, a series of markers have been studied; among them, markers of inflammation have attracted attention given the role of inflammation in carcinogenesis [39].

3.1. Systemic Inflammatory Response. An increasing number of studies have focused on the role of the systemic inflammatory response (SIS) as a prognostic factor in cancer [40]. The pathogenesis of SIS is unknown. However, some hypotheses have been postulated. It has been suggested that SIS may be 
the effect of the tumour hypoxia or necrosis or the consequence of the local tissue injury [41]. The most used biomarkers that reflect a SIS are white blood cell subtypes and C-reactive protein (CRP).

3.1.1. NLR, LMR, and PLR. One of the most studied markers is the neutrophil-to-lymphocyte ratio (NLR). In many studies, NLR has been shown to be an unfavourable prognostic indicator for various diseases including neoplasia. Moreover, an increased NLR correlates with chronic inflammation [42]. A systematic review by Guthrie et al. showed that NLR is increased in patients with advanced and aggressive cancers [40].

Charles et al. performed a study on 145 patients with head and neck squamous cell carcinoma (HNSCC) and concluded that NLR can be used as a prognostic factor and a value higher than 5 is associated with a shorter survival; therefore, these patients should receive additional therapies that might prevent this outcome. In addition, it seems that NLR could be used to identify those patients at risk of relapse [43]. In line with this, in patients with oral cancer, Tsai et al. identified leukocytosis, monocytosis, neutrophilia, and elevated values of NLR associated with advanced cancer and undifferentiated tumour [44]. Moreover, Perisanidis et al. analysed 97 patients with OSCC with local invasion who were preoperatively treated with chemotherapy and observed that NLR is an independent marker for an unfavourable prognosis [45].

Eltohami et al. proposed SIS as a predictive factor in OSCC. To assess SIS, they determined the albumin level and lymphocyte-to-monocyte ratio (LMR). Low values of albumin level and LMR have been associated with advanced stages of the tumour. The low level of albumin was explained by the protein loss that accompanied advanced tumours [46]. Park et al. suggested a prognostic score system, which included the determination of NLR, LMR, and platelet-tolymphocyte ratio (PLR). To assess the effectiveness of the score, they performed a study on 69 patients with OSCC and determined the aforementioned parameters. Low LMR and increased NLR and PLR were associated with highgrade lesions. Decreased LMR and increased NLR correlated with tumour size and increased PLR with significant lymph node involvement. These biomarkers could be useful in the follow-up of patients with OSCC [47].

3.1.2. CRP. CRP is an acute-phase protein belonging to the pentraxin family. CRP is synthesized in the hepatocytes, primarily under the stimulation of IL-1 and IL-6. Elevated serum levels occur in case of inflammation, infection, or injury [48]. It is worth pointing out that a tumour can trigger an inflammatory response, resulting in the release of proinflammatory cytokines such as IL-6 and IL- $1 \beta$. Thus, an increasing number of studies have revealed elevated levels of CRP in cancer [49, 50]. However, the direct link between CRP and cancer is still a debatable topic.

Allin et al. conducted a study that included 10,408 individuals, selected from the general population, and measured the serum levels of CRP. The subjects were followed for up to 16 years, and 1624 of them developed a type of cancer. The study demonstrated that elevated levels of CRP in individuals without cancer represent a risk factor for the development of a type of cancer [51]. In line with this, the meta-analysis by Guo et al. has shown that elevated levels of CRP are associated with an increased risk of cancer. In fact, the relationship between cancer and inflammation is bidirectional. The tumour leads to an inflammatory response including increased serum levels of CRP on the one hand, and chronic inflammation can be involved in the development of a malignant process, on the other hand [52].

The study by Metgud and Bajaj assessed serum and salivary levels of CRP in 20 patients with premalignant lesions, 20 OSCC patients, and 20 healthy subjects. Serum and salivary levels of CRP were highest in OSCC patients, and the lowest values were recorded in healthy subjects. CRP levels showed a graded increase according to the severity of the tumour. They suggested that CRP could be regarded as a prognosis marker in OSCC [53]. Khandavilli et al. highlighted that the elevated level of preoperative CRP is an unfavourable prognostic indicator [54].

Moreover, Chen et al. proposed CRP as a potential marker of OSCC aggressiveness. They found elevated levels of CRP in patients with advanced disease and lymph nodes or bone involvement. In addition, there was an association with the prognosis of the disease, patients with elevated CRP levels having a lower survival rate [55]. The same idea is supported by the study of Tai et al. on 343 patients with OSCC, which has shown a positive correlation between high CRP levels $(\geq 5.0 \mathrm{mg} / \mathrm{L})$ and oral cancer and revealed that the CRP level correlated with local and lymph nodes invasion. Regarding OSCC localisation, the best correlations were obtained in the case of buccal mucosa involvement [56].

Some investigators studied CRP in conjunction with other parameters. The study by Blatt revealed that CRP, hemoglobin, and ferritin could be used as biomarkers in prognosis and disease progression [57]. In the study by Park, the increased CRP/albumin ratio was associated with disease extension and a low survival rate, proving to be an accessible and useful marker for prognosis [58]. In addition, another study identified that elevated levels of CRP; a high number of total leukocytes, monocytes, and neutrophils; and a low number of lymphocytes correlate with a low survival rate in OSCC patients [59].

3.2. NF- $\kappa B$. The nuclear factor kappa-beta (NF- $\kappa \mathrm{B})$ belongs to the Rel/NF- $\kappa$ B family of transcription factors [60]. The activation of NF- $\kappa \mathrm{B}$, a key event in the inflammatory process, is identified in various tumours and linked to carcinogenesis. $\mathrm{NF}-\kappa \mathrm{B}$ has been shown to be involved in angiogenesis, inhibition of apoptosis, and cell proliferation [61,62]. The activation of NF- $\kappa \mathrm{B}$ is initiated by various stimuli such as carcinogens, viral proteins, oncogenes, or infectious stimuli. The overexpression of NF- $\kappa$ B has been identified in many tumours, and its suppression has been associated with the inhibition of cell proliferation and promotion of apoptosis [63].

However, the role of NF- $\kappa \mathrm{B}$ in carcinogenesis is controversial. The study by Piva et al. revealed a positive correlation between the overexpression of NF- $\kappa \mathrm{B}$ and the amount of inflammatory infiltrate in oral dysplastic lesions [64]. The study conducted by Bancroft emphasized that the increased 
expression of IL- $1 \alpha$ in HNSCC induces the activation of transcriptional factors, NF- $\kappa \mathrm{B}$ and AP-1, and IL- 8 expression. Furthermore, they observed that the epidermal growth factor receptor (EGFR) promotes $\mathrm{NF}-\kappa \mathrm{B}$ activation in a murine model of SCC. Studies have shown that the inhibition of NF$\kappa \mathrm{B}$ and EGFR is associated with beneficial effects in HNSCC resulting in the prevention of cell proliferation and stimulation of a cytotoxic response [65]. In contrast, van Hogerlinden et al. found that the inhibition of Rel/NF- $\kappa \mathrm{B}$ signalling in epithelial cells leads to an imbalance in cell development and differentiation with increased apoptosis of keratinocytes and the de novo appearance of squamous cell carcinomas. Thus, in a particular context, NF- $\kappa \mathrm{B}$ inhibition may play a role in the development of a malignant tumour [66].

The study by Alam et al. analysed whether there is a correlation between $\mathrm{B}$-cell lymphoma protein 2 (BCL-2) gene expression and $\mathrm{AP}-1$ and $\mathrm{NF}-\kappa \mathrm{B}$ transcription factors. They evaluated samples of normal mucosa, primary oral tumour (PT), and recurrent chemo- and radioresistant oral tumour (RCRT). Regarding NF- $\kappa \mathrm{B}$, the best correlation was observed with BCL-2 protein in the PT group and in the case of AP-1 in the RCRT group, suggesting the role of the two transcription factors in tumour progression or treatment resistance [67]. Wei et al. demonstrated that activation of NF- $\kappa \mathrm{B}$ and hedgehog signalling pathways is associated with lower survival in those patients with esophageal SCC [68].

3.3. Cytokines. Cytokines are small proteins that in the past were called lymphokines or monokines depending on the cells that produced them. It is now known that any nucleated cell has the ability to secrete cytokines, but their main cell source is represented by helper $\mathrm{T}$ cells and macrophages $[69,70]$.

Cytokines have a key role in modulation of the immune response and are classified into two broad groups, proinflammatory (IL-1, IL-6, IL-8, TNF- $\alpha$, and TGF- $\beta$ ) and antiinflammatory (IL-2, IL-12, IL-4, IL-10, and IFN- $\gamma$ ) cytokines [71]. Among the cytokines that may be involved in oral cancer, interleukins seem to have a crucial function, the most studied being IL-4, IL-6, IL-8, and IL-10 [72].

3.3.1. Proinflammatory Cytokines - IL-6 and IL-8. IL-6 is synthesized in acute inflammatory response contributing to host defence. It has been shown to be involved in processes such as inflammation, immune response control, hematopoiesis, and oncogenesis. However, under certain conditions, elevated levels of IL- 6 may lead to disturbances of the immune response [71, 73-75]. IL-6 can induce the transition from acute to chronic inflammation by recruiting monocytes to the site of inflammation through monocyte chemoattractant protein-1 (MCP-1) secretion [76].

Another proinflammatory cytokine which attracted the attention of investigators is IL-8, considered the prototype molecule in the chemokine class. IL- 8 plays also an important role in the acute inflammatory response and persists for a relatively long time at the site of inflammation [77]. Its release from macrophages and neutrophils is activated by NF- $\kappa \mathrm{B}$. Moreover, its expression is modulated by other various stimuli, such as inflammation, hypoxia, or steroid hormones. IL- 8 binds to CRCX-1 and CRCX-2 receptors which have been identified both on inflammatory cells from the tumour-associated infiltrate and tumour cells $[78,79]$.

Wang et al. analysed 86 samples of OSCC and noticed higher expression of IL-6 receptor (IL-6R) and IL-6 mRNA compared to samples from tumour-free mucosa. The study revealed a positive association between IL-6R expression, tumour size, and histopathological stage. Moreover, expression of IL- 6 mRNA was correlated with advanced disease (lymph node involvement and distant metastases) [80]. Sato et al. suggested that the posttreatment level of IL- 6 might be a marker for the early detection of a locoregional recurrence [81]. In addition, it seems that IL-6 expression is associated with resistance to chemotherapy [82].

Schiegnitz et al. showed higher serum levels of IL-6, IL-8, and soluble IL-2 receptor (sIL-2R) in patients with OSCC compared to those with oral premalignant lesions and healthy subjects. Regarding the differentiation of oral premalignant lesions by OSCC, the best results were based on the IL-6 level. Higher sensitivity and specificity were obtained by measuring the levels of both IL-6 and IL-8. [83]. Similarly, Punyani and Sathawane analysed the salivary level of IL-8 in patients with premalignant oral lesions and OSCC and in a control group. They found a statistically significantly higher salivary level of IL-8 in patients with OSCC than in those with premalignant lesions. However, no statistical significance was obtained when comparing the premalignant group with the control group. They suggested that the salivary level of IL- 8 could be used as a biomarker for OSCC, but not for premalignant lesions [84]. The study by Rao et al. showed that IL- 8 could be involved in tumourigenesis by activating NF- $\kappa \mathrm{B}$ and STAT signalling pathways and concluded that chronic inflammation plays a key role in malignant transformation, IL- 8 being a modulator of inflammation that should not be neglected [85].

Other research has also investigated the possible role of salivary cytokines in OSCC detection. The study included 9 patients with OSCC and 9 healthy subjects; TNF- $\alpha$, IL- $1 \alpha$, IL-6, and IL-8 were measured. However, only the salivary levels of IL- 6 were statistically significantly higher in patients with OSCC compared to the control group [39].

The study by Lee et al. on 41 patients with OSCC and 24 patients without oral malignant lesions evaluated an extended group of biomarkers in both plasma and saliva. The salivary determinations of eotaxin, IFN- $\gamma$, macrophage inflammatory proteins- (MIP-) $1 \beta$, IL- $1 \beta$, IL- 6 , IL- 8 , and TNF- $\alpha$ were significantly higher in OSCC compared to controls. Regarding plasma determinations, significant differences between groups were observed only for IFN- $\gamma$-inducible protein 10 (IP10). Elevated plasma levels of eotaxin, granulocyte colony-stimulating factor (GCSF), and IL-6 were detected in advanced stages, and they have been proposed as markers of advanced OSCC [86].

In contrast, Czerninski et al. investigated the serum levels of IL-1, IL-6, IL-8, IL-10, and soluble IL-2 receptor in patients with precancerous oral lesions, OSCC, and postOSCC status and they did not find statistically significant differences between the studied groups. They concluded that the investigation of serum levels of these parameters has little utility in the early detection of OSCC [87]. 
3.3.2. Anti-inflammatory Cytokines - IL-10 and IL- 4. IL-10 is one of the most important interleukins with an antiinflammatory role, being produced by numerous activated cells (B and T lymphocytes, macrophages, mast cells, etc.). IL-10 inhibits the release of proinflammatory mediators from macrophages and the antigen presentation [88]. IL-4 also exhibits an inhibitory effect on inflammation and angiogenesis and is particularly secreted by activated memory $\mathrm{T}$ cells [89]. IL-10 and IL-4 suppress the local immune response and mediate the recruitment of regulatory $\mathrm{T}$ cells and TAM in the tumour microenvironment [12]. Moreover, it seems that IL-4 may inhibit the invasion in oral cancers by decreasing matrix-metalloproteinase(MMP-) 9 expression [90].

The study by Arantes et al., which focused on the analysis of anti-inflammatory cytokines in OSCC patients, showed a higher expression of IL-10 and TGF- $\beta 2$ in OSCC samples compared to normal mucosa [91]. The same result regarding IL-10 was obtained by Alhamarneh et al., who suggested that IL-10 could be an unfavourable prognostic factor. The serum level of IL-10 was statistically significantly higher in OSCC patients compared to the control group [92]. Another study evaluated the role of immunosuppressive cytokines (IL-4, IL-10, IL-13, and IL-1 receptor antagonist-IL-1RA) in the early detection of OSCC on 30 patients with OSCC and 33 healthy subjects. Salivary levels of IL-10 and IL-13 were significantly higher in OSCC patients compared to normal subjects. Therefore, the study concluded that IL-10 and IL-13 could be used as biomarkers in OSCC diagnosis. In addition, it was highlighted that IL-1RA levels were higher in those with undifferentiated tumour compared to those with differentiated tumour [93]. Another study associated the increased expression of IL-10 in tumour cells with a more aggressive tumour phenotype [94]. In contrast, the study by Hamzavi et al. on 30 patients with HNSCC and 24 normal controls found no statistically significant differences between the two groups with respect to the salivary and serum IL-10 level. However, the tissue analysis revealed that IL-10 expression was positive in $86 \%$ of patients with OSCC and was not identified in controls [95]. A recent study has suggested that IL-10 could be involved in the immune evasion of tumour cells. A percentage of $91 \%$ of OSCC samples exhibited an increased expression of IL-10 [96].

Tsai et al. observed that there was an association between IL-4 genes -590 C/T polymorphism and oral cancer, suggesting that it might represent a marker in oral cancer detection [97]. The study by Sun et al. which assessed the expression of several cytokines in OLP, OLK, and OSCC revealed increased expression of IL-4 in OSCC compared to OLK and OLP and raised the hypothesis that IL-4 has a low immunosuppressive role in the tumour microenvironment [12]. The study by Beppu et al. highlighted that IL- 4 can suppress NF- $\kappa$ B activation and increase the production of MMP9 in TNF- $\alpha$-stimulated cells. Regarding IL-10, they did not observe these effects [90].

3.4. Cyclooxygenases. It has been observed that the association between increased expression of cyclooxygenase(COX-) 2 and chronic inflammation is involved in the initiation of a carcinogenic process. Cyclooxygenases are enzymes that convert arachidonic acid to prostaglandins. Two main isoforms, COX-1 and COX-2, have been described [98]. COX-1 is expressed by the majority of cells and participates in various physiological events [99]. In contrast, under normal conditions, COX-2 is not expressed in the cells of the body, but under the influence of certain stimuli such as inflammation, it will be expressed [100]. Thus, COX-2 plays an important role in inflammation, but in recent years its role in carcinogenesis has also been studied. It seems that COX-2 is directly or indirectly involved in cell proliferation, inhibition of apoptosis, and angiogenesis $[99,101]$. The role of COX-2 in carcinogenesis is also suggested by studies which have revealed a lower risk of developing a malignant tumour in those patients receiving COX-2 inhibitors [102]. Patel et al. pointed out that COX-2 overexpression could be correlated with the risk of recurrence of OSCC [103].

Sinanoglu et al. proposed COX-2 and Ki67 as biomarkers for the malignant transformation of oral leukoplakia. They revealed a higher COX-2 expression in OSCC samples compared to oral intraepithelial leukoplakia and oral hyperkeratosis, with a positive correlation between COX-2 levels and the severity of the lesions being observed. Similar results were found for Ki67 [104]. The study by Seyedmajidi et al. revealed higher COX-2 levels in OSCC compared to dysplastic and normal mucosal lesions. COX-2 levels showed a graded increase according to the severity of dysplastic lesions, but no correlation has been obtained with the severity of OSCC lesions [105]. In contrast, the study by Shibata et al. analysed normal, dysplastic, and OSCC samples and observed higher COX-1 and COX-2 levels in dysplastic lesions compared to OSCC; the levels increased according to the severity of the lesions, a fact that suggests the role of COX-1 and COX-2 as markers of early carcinogenesis. In OSCC lesions, a negative correlation between COX-1 and COX-2 levels and tumour histological grade was observed [106].

3.5. Matrix Metalloproteinases. Matrix metalloproteinases (MMPs) are a family of zinc-dependent enzymes, which encompass over 20 members with proteolytic activity that can disintegrate almost any extracellular matrix component. MMPs take part to many physiological processes such as tissue remodelling or regeneration but also in pathological conditions such as inflammation and tumourigenesis, by abnormal activation [107-109]. MMPs are involved in cell migration and regulate the level of cytokines at the site of inflammation, where, in turn, activated inflammatory cells release MMPs. It is worth noting that under such conditions, MMPs act on non-matrix substrates. It seems that they can activate or inactivate cytokine functions and subsequently promote or inhibit the inflammatory response [110]. Studies increasingly link MMPs to cancer [111, 112]. The main mechanisms postulated which support the hypothesis that MMPs participate in carcinogenesis include regulation of tumour cell growth and angiogenesis, modulation of apoptosis, extracellular matrix degradation, which facilitates tumour invasion, and epithelial to mesenchymal transition $[107,113]$. Several researchers have analysed the role of MMPs as markers in OSCC. 
The study by Chang et al., which investigated markers of inflammation in patients with oral leukoplakia and OSCC, showed that the most reliable markers are MMP-2, MMP9, CRP, TGF- $\beta 1$, and E-selectin. MMP-9 was the marker that best correlated with the evolution from normal tissue to leukoplakia and neoplasm. In addition, the study showed that the risk of relapse is greatest in patients with CRP $\geq 2 \mathrm{mg} / \mathrm{L}$ and $\mathrm{E}-$ selectin $\geq 85 \mathrm{ng} / \mathrm{mL}$ at baseline. The panel of the five studied markers was associated with a sensitivity of $67.4 \%$ for premalignant lesions and $80 \%$ for malignant tumours and a specificity of $90 \%$, for the identification of the patients at risk of malignant transformation [114]. Another recent study has suggested that MMP-10 could also be a marker of malignant transformation of normal mucosa into OSCC [115].

Makinen et al. evaluated the expression of MMP-7 and MMP-25 in 73 patients with oral tongue SCC in an early stage. A percentage of $90 \%$ of the tumours expressed MMP7 and MMP-25. The increased expression of MMP-7 was identified in poorly differentiated tumours and correlated with a higher risk of ocular metastases and a higher degree of local invasion. In contrast, MMP-25 expression did not correlate with any prognostic factors [116]. The study by Lawal et al. highlighted the increased expression of MMP-2 in poorly differentiated OSCC and a lack of expression of MMP-8; MMP-8 was identified in well-differentiated tumours. They suggested that MMP-2 could be a marker of tumour aggressiveness, and MMP-2 inhibitors could be used in therapy [117].

One of the phenomena that occur during the local invasion and subsequent metastasis is the degradation of the extracellular matrix and basal membrane [115]. Based on this fact, Tanis et al. evaluated the potential role of MMPs in metastatic OSCC. They included 12 patients with metastatic OSCC and 12 healthy controls and emphasized that the expression of MMP-1, MMP-3, MMP-9, and MMP-10 was greatest in those with metastatic OSCC, demonstrating the role of MMPs as early markers of metastatic tumour [118].

3.6. Galectins. Galectins are animal lectins with affinity for beta-galactosides. Galectins contain carbohydraterecognition domains, which are involved in carbohydrate binding. Carbohydrate binding activity plays an important role in the various functions of galectins [119]. Numerous studies have investigated the expression of galectins in cancer patients. To date, according to the meta-analysis of Thijssen, there are over 200 studies, and most of them (>70\%) have analysed the expression of galectin- (gal-) 1 and gal-3. With regard to the type of cancer, over half of the studies included patients with cancers of digestive or reproductive system [120]. In neoplasms, galectins have a dual role, pro- or antitumoural, depending on the type of cancer [121]. It seems that galectins modulate various biological processes, being regulators of adaptive immunity, homeostasis, tissue regeneration, and angiogenesis [122]. Galectins participate in immune response through diverse mechanisms, including the promotion of inflammation, stimulation of $\mathrm{T}$ cells, and modulation of regulatory $\mathrm{T}$ cell activity [9].

Noda et al. showed that the evaluation of the immunohistochemical expression of gal-1 in samples taken from the oral cavity could discriminate between neoplastic processes and reactive changes, decreasing the rate of false-positive and -negative results [123]. In addition, it could be used as a prognostic factor [124]. Aggarwal et al. proposed serum levels of gal-1 and gal-3 as screening markers for those patients at high risk of developing OSCC [125]. Another study has suggested the role of gal-9 in differentiating OSCC from premalignant lesions. Muniz et al. assessed the expression of gal-1, gal-3, and gal-9 in 40 OSCC samples and 40 premalignant lesions (20 OLP and 20 OLK) and 13 normal tissue samples. The expression of gal-9 was significantly higher in OSCC samples compared to premalignant lesions and healthy tissue. With respect to gal-1 and gal-3, the results were variable [126].

Mesquita et al. assessed the immunohistochemical expression of gal-3 and gal-7 in correlation with tumour clinical stage and histopathological grade in 32 patients younger than 45 years with OSCC. Gal-3 expression was identified in $65.6 \%$ of cases and did not correlate with the two studied parameters. In contrast, gal-7 expression was observed in a higher percentage, $96.9 \%$, and a statistically significant correlation with the histological grade was obtained [127]. Another study suggested that gal-7 could be used as a marker of resistance to chemo and/or radiotherapy [128].

3.7. Markers of Oxidative Stress. Under physiological conditions, reactive oxygen species (ROS) exert beneficial effects being involved in the fight against infectious agents and preservation of cell homeostasis. However, under pathological conditions, the most common being conditions associated with chronic inflammation, ROS levels are increased and exhibit deleterious effects on cell components (lipids, proteins, and nucleic acids) [129-131]. The main consequence of chronic inflammation is an imbalance between oxidants and antioxidants, with increased production of ROS and decreased antioxidant protection. It was demonstrated that ROS are involved in carcinogenesis exerting effects on cell proliferation and apoptosis. It seems that ROS are the main chemical effectors acting at tissue level [132-135].

Huo et al. found elevated levels of ROS associated with low levels of antioxidant enzymes, in both blood and tumour tissue of the patients with OSCC. They revealed high levels of malondialdehyde (MDA) and nitric oxide (NO) and low levels of superoxide dismutase (SOD) and catalase (CAT) compared to the control group, suggesting the role of the imbalance between oxidants and antioxidants in carcinogenesis [136]. The same idea is supported by the study of Kumar et al. on 100 patients with HNSCC and 90 healthy subjects. The increased levels of ROS were associated with reduction of salivary total antioxidant capacity (TAC) and glutathione (GSH) level [137]. The study by Subapriya et al. revealed differences between the oxidative stress markers in tumour tissue and blood. Tissue determinations showed low lipid peroxidation in association with increased GSH-dependent antioxidant capacity. In contrast, increased lipid peroxidation and low antioxidant levels were detected in blood. It was therefore suggested that increased GSH-dependent antioxidant capacity represents the basis of a selective 
development of cancer cells which is detrimental to the normal cells. The results obtained from blood are explained by the sequestration phenomenon of antioxidants in the tumour cells and the susceptibility of erythrocytes to lipid peroxidation induced by ROS [138].

Manoharan et al. have identified that the levels of thiobarbituric acid reactive substances (TBARS) and antioxidants correlate with tumour status; there was a progressive increase in TBARS levels and a decrease in antioxidants levels from stage II to stage IV [139].

\section{Conclusion}

OSCC, a tumour with a local invasive behaviour and an important metastatic capacity, would benefit from an early diagnosis, which in turn may contribute to a more favourable outcome. Starting from the hypothesis that inflammation plays an important role in carcinogenesis, various markers have been investigated in order to elucidate the involvement of different inflammation pathways in OSCC pathogenesis. Thus, either common markers such as serum CRP or white blood cell subtypes, as well as more sophisticated markers such as MMPs or COX-2, may provide new insights into the molecular mechanisms of tumour development and progression and could open new pathways in diagnosis, prognosis, and therapeutic approach for OSCC. The quest for the ideal biomarkers in oral cancer is currently ongoing, and further studies are needed in order to establish the most reliable candidate markers with the greatest impact on both scientific research and clinical practice.

\section{Conflicts of Interest}

The authors declare no conflict of interests.

\section{Authors' Contributions}

All authors have equally contributed to writing and editing the manuscript.

\section{Acknowledgments}

This work was partially supported by a grant of the Romanian Ministry of Research and Innovation, CCCDIUEFISCDI (project number 61PCCDI/2018 PN-III-P1-1.2PCCDI-2017-0341), within PNCDI-III.

\section{References}

[1] K. Omura, "Current status of oral cancer treatment strategies: surgical treatments for oral squamous cell carcinoma," International Journal of Clinical Oncology, vol. 19, no. 3, pp. 423430, 2014.

[2] A. Bulman, M. Neagu, and C. Constantin, "Immunomics in skin cancer - improvement in diagnosis, prognosis and therapy monitoring," Current Proteomics, vol. 10, no. 3, pp. 202-217, 2013.

[3] P. J. Thomson, "Perspectives on oral squamous cell carcinoma prevention-proliferation, position, progression and prediction," Journal of Oral Pathology \& Medicine, vol. 47, no. 9, pp. 803-807, 2018.

[4] A. K. Markopoulos, "Current aspects on oral squamous cell carcinoma," The Open Dentistry Journal, vol. 6, no. 1, pp. 126-130, 2012.

[5] C. Scully and J. Bagan, "Oral squamous cell carcinoma overview,” Oral Oncology, vol. 45, no. 4-5, pp. 301-308, 2009.

[6] S. R. Georgescu, M. I. Sârbu, C. Matei et al., "Capsaicin: friend or foe in skin cancer and other related malignancies?," Nutrients, vol. 9, no. 12, p. 1365, 2017.

[7] S. R. Georgescu, C. D. Ene, I. L. Nicolae et al., "Reflectometric analysis for identification of various pathological conditions associated with lichen planus," Revista de Chimie, vol. 68, no. 5, pp. 1103-1108, 2017.

[8] K. Kansy, O. Thiele, and K. Freier, "The role of human papillomavirus in oral squamous cell carcinoma: myth and reality," Oral and Maxillofacial Surgery, vol. 18, no. 2, pp. 165-172, 2014.

[9] M. Tampa, C. Caruntu, M. Mitran et al., "Markers of Oral lichen planus malignant transformation," Disease Markers, vol. 2018, Article ID 1959506, 13 pages, 2018.

[10] C. Matei, M. Tampa, R. M. Ion, M. Neagu, and C. Constantin, "Photodynamic properties of aluminium sulphonated phthalocyanines in human displazic oral keratinocytes experimental model," Digest Journal of Nanomaterials \& Biostructures, vol. 7, no. 4, pp. 1535-1547, 2012.

[11] C. Matei, M. Tampa, C. Caruntu et al., "Protein microarray for complex apoptosis monitoring of dysplastic oral keratinocytes in experimental photodynamic therapy," Biological Research, vol. 47, no. 1, p. 33, 2014.

[12] Y. Sun, N. Liu, X. Guan, H. Wu, Z. Sun, and H. Zeng, "Immunosuppression induced by chronic inflammation and the progression to oral squamous cell carcinoma," Mediators of Inflammation, vol. 2016, Article ID 5715719, 12 pages, 2016.

[13] M. Lupu, A. Caruntu, C. Caruntu et al., "Non-invasive imaging of actinic cheilitis and squamous cell carcinoma of the lip," Molecular and Clinical Oncology, vol. 8, no. 5, pp. 640646, 2018.

[14] F. Balkwill and A. Mantovani, "Inflammation and cancer: back to Virchow?," The Lancet, vol. 357, no. 9255, pp. 539$545,2001$.

[15] A. Vallée and Y. Lecarpentier, "Crosstalk between peroxisome proliferator-activated receptor gamma and the canonical WNT/ $\beta$-catenin pathway in chronic inflammation and oxidative stress during carcinogenesis," Frontiers in Immunology, vol. 9, p. 745, 2018.

[16] M. Neagu, C. Caruntu, C. Constantin et al., "Chemically induced skin carcinogenesis: updates in experimental models (Review)," Oncology Reports, vol. 35, no. 5, pp. 2516-2528, 2016.

[17] D. F. Quail and J. A. Joyce, "Microenvironmental regulation of tumor progression and metastasis," Nature Medicine, vol. 19, no. 11, pp. 1423-1437, 2013.

[18] K. E. De Visser, A. Eichten, and L. M. Coussens, "Paradoxical roles of the immune system during cancer development," Nature Reviews Cancer, vol. 6, no. 1, pp. 24-37, 2006.

[19] P. Allavena, C. Garlanda, M. G. Borrello, A. Sica, and A. Mantovani, "Pathways connecting inflammation and cancer," Current Opinion in Genetics \& Development, vol. 18, no. 1, pp. 3-10, 2008. 
[20] S. I. Grivennikov, F. R. Greten, and M. Karin, "Immunity, inflammation, and cancer," Cell, vol. 140, no. 6, pp. 883899, 2010.

[21] M. Jinushi and Y. Komohara, "Tumor-associated macrophages as an emerging target against tumors: creating a new path from bench to bedside," Biochimica et Biophysica Acta (BBA) - Reviews on Cancer, vol. 1855, no. 2, pp. 123-130, 2015.

[22] L. Feller, M. Altini, and J. Lemmer, "Inflammation in the context of oral cancer," Oral Oncology, vol. 49, no. 9, pp. 887-892, 2013.

[23] B. Calenic, M. Greabu, C. Caruntu, C. Tanase, and M. Battino, "Oral keratinocyte stem/progenitor cells: specific markers, molecular signaling pathways and potential uses," Periodontology 2000, vol. 69, no. 1, pp. 68-82, 2015.

[24] S. Kullage, M. Jose, V. K. L. Shanbhag, and R. Abdulla, "Qualitative analysis of connective tissue stroma in different grades of oral squamous cell carcinoma: a histochemical study," Indian Journal of Dental Research, vol. 28, no. 4, pp. 355361, 2017.

[25] F. A. P. da Cunha Filho, M. C. F. de Aguiar, L. B. de Souza et al., "Immunohistochemical analysis of FoxP3+ regulatory T cells in lower lip squamous cell carcinomas," Brazilian Oral Research, vol. 30, no. 1, 2016.

[26] D. R. Camisasca, M. A. N. C. Silami, J. Honorato, F. L. Dias, P. A. S. d. Faria, and S. d. Q. C. Lourenço, "Oral squamous cell carcinoma: clinicopathological features in patients with and without recurrence," ORL, vol. 73, no. 3, pp. 170-176, 2011.

[27] F. Mashhadiabbas and M. Fayazi-Boroujeni, "Correlation of vascularization and inflammation with severity of oral leukoplakia," Iranian Journal of Pathology, vol. 12, no. 3, pp. 225230, 2017.

[28] L. Lo Muzio, A. Santoro, T. Pieramici et al., "Immunohistochemical expression of CD3, CD20, CD45, CD68 and bcl-2 in oral squamous cell carcinoma," Analytical and Quantitative Cytology and Histology, vol. 32, no. 2, pp. 70-77, 2010.

[29] A. C. A. Pellicioli, L. Bingle, P. Farthing, M. A. Lopes, M. D. Martins, and P. A. Vargas, "Immunosurveillance profile of oral squamous cell carcinoma and oral epithelial dysplasia through dendritic and T-cell analysis," Journal of Oral Pathology \& Medicine, vol. 46, no. 10, pp. 928-933, 2017.

[30] J. Fang, X. Li, D. Ma et al., "Prognostic significance of tumor infiltrating immune cells in oral squamous cell carcinoma," BMC Cancer, vol. 17, no. 1, p. 375, 2017.

[31] N. Meyer and A. C. Zenclussen, "Mast cells—good guys with a bad image?," American Journal of Reproductive Immunology, vol. 80, no. 4, article e13002, 2018.

[32] A. Rigoni, M. P. Colombo, and C. Pucillo, "The role of mast cells in molding the tumor microenvironment," Cancer Microenvironment, vol. 8, no. 3, pp. 167-176, 2015.

[33] A. Tahir, A. H. Nagi, E. Ullah, and O. S. Janjua, "The role of mast cells and angiogenesis in well-differentiated oral squamous cell carcinoma," Journal of Cancer Research and Therapeutics, vol. 9, no. 3, pp. 387-391, 2013.

[34] Ł. Pyziak, O. Stasikowska-Kanicka, M. Danilewicz, and M. Wągrowska-Danilewicz, "Immunohistochemical analysis of mast cell infiltrates and microvessel density in oral squamous cell carcinoma," Polish Journal of Pathology, vol. 64, no. 4, pp. 276-280, 2013.
[35] C. Căruntu, D. Boda, S. Musat, A. Căruntu, and E. Mandache, "Stress-induced mast cell activation in glabrous and hairy skin," Mediators of Inflammation, vol. 2014, Article ID 105950, 9 pages, 2014.

[36] M. Kalra, N. Rao, K. Nanda et al., "The role of mast cells on angiogenesis in oral squamous cell carcinoma," Medicina Oral Patología Oral y Cirugia Bucal, vol. 17, pp. e190-e196, 2012.

[37] A. Kabiraj, R. Jaiswal, A. Singh, J. Gupta, A. Singh, and F. M. Samadi, "Immunohistochemical evaluation of tumor angiogenesis and the role of mast cells in oral squamous cell carcinoma," Journal of Cancer Research and Therapeutics, vol. 14, no. 3, pp. 495-502, 2018.

[38] S. Jain, R. G. Phulari, R. Rathore, A. K. Shah, and S. Sancheti, "Quantitative assessment of tumor-associated tissue eosinophilia and mast cells in tumor proper and lymph nodes of oral squamous cell carcinoma," Journal of Oral and Maxillofacial Pathology, vol. 22, no. 1, p. 145, 2018.

[39] M. SahebJamee, M. Eslami, F. AtarbashiMoghadam, and A. Sarafnejad, "Salivary concentration of TNF $\alpha$, IL1 $\alpha$, IL6, and IL8 in oral squamous cell carcinoma," Medicina Oral Patologia Oral y Cirugia Bucal, vol. 13, no. 5, p. 292, 2008.

[40] G. J. K. Guthrie, K. A. Charles, C. S. D. Roxburgh, P. G. Horgan, D. C. McMillan, and S. J. Clarke, "The systemic inflammation-based neutrophil-lymphocyte ratio: experience in patients with cancer," Critical Reviews in Oncology/Hematology, vol. 88, no. 1, pp. 218-230, 2013.

[41] D. C. McMillan, "Systemic inflammation, nutritional status and survival in patients with cancer," Current Opinion in Clinical Nutrition and Metabolic Care, vol. 12, no. 3, pp. 223-226, 2009.

[42] M. A. O. Magalhaes, J. E. Glogauer, and M. Glogauer, "Neutrophils and oral squamous cell carcinoma: lessons learned and future directions," Journal of Leukocyte Biology, vol. 96, no. 5, pp. 695-702, 2014.

[43] K. A. Charles, B. D. W. Harris, C. R. Haddad et al., "Systemic inflammation is an independent predictive marker of clinical outcomes in mucosal squamous cell carcinoma of the head and neck in oropharyngeal and non-oropharyngeal patients," BMC Cancer, vol. 16, no. 1, p. 124, 2016.

[44] Y. D. Tsai, C. P. Wang, C. Y. Chen et al., "Pretreatment circulating monocyte count associated with poor prognosis in patients with oral cavity cancer," Head \& Neck, vol. 36, no. 7, pp. 947-953, 2014.

[45] C. Perisanidis, G. Kornek, P. W. Pöschl et al., "High neutrophil-to-lymphocyte ratio is an independent marker of poor disease-specific survival in patients with oral cancer," Medical Oncology, vol. 30, no. 1, p. 334, 2013.

[46] Y. I. Eltohami, H.-K. Kao, W. W.-K. Lao et al., "The prediction value of the systemic inflammation score for oral cavity squamous cell carcinoma," Otolaryngology-Head and Neck Surgery, vol. 158, no. 6, pp. 1042-1050, 2018.

[47] Y. M. Park, K. H. Oh, J. G. Cho et al., "A prognostic scoring system using inflammatory response biomarkers in oral cavity squamous cell carcinoma patients who underwent surgery-based treatment," Acta Oto-Laryngologica, vol. 138, no. 4, pp. 422-427, 2018.

[48] S. B. Asegaonkar, B. N. Asegaonkar, U. V. Takalkar, S. Advani, and A. P. Thorat, "C-reactive protein and breast cancer: new insights from old molecule," International Journal of Breast Cancer, vol. 2015, Article ID 145647, 6 pages, 2015. 
[49] K. Saito and K. Kihara, "Role of C-reactive protein in urological cancers: a useful biomarker for predicting outcomes," International Journal of Urology, vol. 20, no. 2, pp. 161-171, 2013.

[50] V. Voiculescu, B. Calenic, M. Ghita et al., "From normal skin to squamous cell carcinoma: a quest for novel biomarkers," Disease Markers, vol. 2016, Article ID 4517492, 14 pages, 2016.

[51] K. H. Allin, S. E. Bojesen, and B. G. Nordestgaard, "Baseline $\mathrm{C}$-reactive protein is associated with incident cancer and survival in patients with cancer," Journal of Clinical Oncology, vol. 27, no. 13, pp. 2217-2224, 2009.

[52] Y.-Z. Guo, L. Pan, C.-J. du, D.-Q. Ren, and X.-M. Xie, "Association between C-reactive protein and risk of cancer: a meta-analysis of prospective cohort studies," Asian Pacific Journal of Cancer Prevention, vol. 14, no. 1, pp. 243-248, 2013.

[53] R. Metgud and S. Bajaj, "Altered serum and salivary Creactive protein levels in patients with oral premalignant lesions and oral squamous cell carcinoma," Biotechnic \& Histochemistry, vol. 91, no. 2, pp. 96-101, 2016.

[54] S. D. Khandavilli, P. Ó. Ceallaigh, C. J. Lloyd, and R. Whitaker, "Serum C-reactive protein as a prognostic indicator in patients with oral squamous cell carcinoma," Oral Oncology, vol. 45, no. 10, pp. 912-914, 2009.

[55] H. H. Chen, I. H. Chen, C. T. Liao, F. C. Wei, L. Y. Lee, and S. F. Huang, "Preoperative circulating C-reactive protein levels predict pathological aggressiveness in oral squamous cell carcinoma: a retrospective clinical study," Clinical Otolaryngology, vol. 36, no. 2, pp. 147-153, 2011.

[56] S. F. Tai, H. T. Chien, C. K. Young et al., "Roles of preoperative C-reactive protein are more relevant in buccal cancer than other subsites," World Journal of Surgical Oncology, vol. 15, no. 1, p. 47, 2017.

[57] S. Blatt, H. Schön, K. Sagheb, P. W. Kämmerer, B. al-Nawas, and E. Schiegnitz, "Hemoglobin, C-reactive protein and ferritin in patients with oral carcinoma and their clinical significance - a prospective clinical study," Journal of Cranio-Maxillofacial Surgery, vol. 46, no. 2, pp. 207-212, 2018.

[58] H. C. Park, M. Y. Kim, and C. H. Kim, "C-reactive protein/albumin ratio as prognostic score in oral squamous cell carcinoma," Journal of the Korean Association of Oral and Maxillofacial Surgeons, vol. 42, no. 5, pp. 243-250, 2016.

[59] M. Grimm, J. Rieth, S. Hoefert et al., "Standardized pretreatment inflammatory laboratory markers and calculated ratios in patients with oral squamous cell carcinoma," European Archives of Oto-Rhino-Laryngology, vol. 273, no. 10, pp. 3371-3384, 2016.

[60] J. Huang, Y. Baum, M. Alemozaffar et al., "C-reactive protein in urologic cancers," Molecular Aspects of Medicine, vol. 45, pp. 28-36, 2015.

[61] C. W. Lin, Y. S. Hsieh, C. H. Hsin et al., "Effects of NFKB1 and NFKBIA gene polymorphisms on susceptibility to environmental factors and the clinicopathologic development of oral cancer," PLoS One, vol. 7, no. 4, article e35078, 2012.

[62] A. S. Baldwin, "Control of oncogenesis and cancer therapy resistance by the transcription factor NF- $\kappa \mathrm{B}$," Journal of Clinical Investigation, vol. 107, no. 3, pp. 241-246, 2001.
[63] S. Shishodia and B. B. Aggarwal, "Nuclear factor- $\kappa$ B: a friend or a foe in cancer?," Biochemical Pharmacology, vol. 68, no. 6, pp. 1071-1080, 2004.

[64] M. R. Piva, L. B. de Souza, P. R. S. Martins-Filho et al., "Role of inflammation in oral carcinogenesis (part II): CD8, FOXP3, TNF- $\alpha$, TGF- $\beta$ and NF- $\kappa$ B expression," Oncology Letters, vol. 5, no. 6, pp. 1909-1914, 2013.

[65] C. C. Bancroft, Z. Chen, J. Yeh et al., "Effects of pharmacologic antagonists of epidermal growth factor receptor, PI3K and MEK signal kinases on NF- $\kappa$ B and AP-1 activation and IL-8 and VEGF expression in human head and neck squamous cell carcinoma lines," International Journal of Cancer, vol. 99, no. 4, pp. 538-548, 2002.

[66] M. van Hogerlinden, B. L. Rozell, L. Ährlund-Richter, and R. ToftgÅrd, "Squamous cell carcinomas and increased apoptosis in skin with inhibited Rel/nuclear factor- $\kappa \mathrm{B}$ signaling," Cancer Research, vol. 59, no. 14, pp. 3299-3303, 1999.

[67] M. Alam, T. Kashyap, K. K. Pramanik, A. K. Singh, S. Nagini, and R. Mishra, "The elevated activation of $\mathrm{NF} \kappa \mathrm{B}$ and $\mathrm{AP}-1$ is correlated with differential regulation of Bcl-2 and associated with oral squamous cell carcinoma progression and resistance," Clinical Oral Investigations, vol. 21, no. 9, pp. 27212731, 2017.

[68] L. Wei, N. Yan, L. Sun, C. Bao, and D. Li, "Interplay between the NF- $\kappa \mathrm{B}$ and hedgehog signaling pathways predicts prognosis in esophageal squamous cell carcinoma following neoadjuvant chemoradiotherapy," International Journal of Molecular Medicine, vol. 41, no. 5, pp. 2961-2967, 2018.

[69] C. A. Dinarello, "Proinflammatory cytokines," Chest, vol. 118, no. 2, pp. 503-508, 2000.

[70] J. M. Zhang and J. An, "Cytokines, inflammation, and pain," International Anesthesiology Clinics, vol. 45, no. 2, pp. 27-37, 2007.

[71] Z. Chen, P. S. Malhotra, G. R. Thomas et al., "Expression of proinflammatory and proangiogenic cytokines in patients with head and neck cancer," Clinical Cancer Research, vol. 5, no. 6, pp. 1369-1379, 1999.

[72] G. Prasad and M. McCullough, "Chemokines and cytokines as salivary biomarkers for the early diagnosis of oral cancer," International Journal of Dentistry, vol. 2013, Article ID 813756, 7 pages, 2013.

[73] M. M. Choudhary, T. J. France, T. N. Teknos, and P. Kumar, "Interleukin-6 role in head and neck squamous cell carcinoma progression," World Journal of Otorhinolaryngology-Head and Neck Surgery, vol. 2, no. 2, pp. 90-97, 2016.

[74] T. Tanaka, M. Narazaki, and T. Kishimoto, "IL-6 in inflammation, immunity, and disease," Cold Spring Harbor Perspectives in Biology, vol. 6, no. 10, p. a016295, 2014.

[75] M. Surcel, C. Constantin, C. Caruntu, S. Zurac, and $\mathrm{M}$. Neagu, "Inflammatory cytokine pattern is sex-dependent in mouse cutaneous melanoma experimental model," Journal of Immunology Research, vol. 2017, Article ID 9212134, 10 pages, 2017.

[76] C. Gabay, "Interleukin-6 and chronic inflammation," Arthritis Research \& Therapy, vol. 8, Supplement 2, p. S3, 2006.

[77] D. G. Remick, "Interleukin-8," Critical Care Medicine, vol. 33, no. 12, pp. S466-S467, 2005.

[78] D. J. J. Waugh and C. Wilson, "The interleukin-8 pathway in cancer," Clinical Cancer Research, vol. 14, no. 21, pp. 67356741, 2008. 
[79] H. A. Sahibzada, Z. Khurshid, R. S. Khan et al., "Salivary IL-8, IL- 6 and TNF- $\alpha$ as potential diagnostic biomarkers for oral cancer," Diagnostics, vol. 7, no. 2, p. 21, 2017.

[80] Y. F. Wang, S. Y. Chang, S. K. Tai, W. Y. Li, and L. S. Wang, "Clinical significance of interleukin-6 and interleukin-6 receptor expressions in oral squamous cell carcinoma," Head \& Neck, vol. 24, no. 9, pp. 850-858, 2002.

[81] J. Sato, M. Ohuchi, K. Abe et al., "Correlation between salivary interleukin-6 levels and early locoregional recurrence in patients with oral squamous cell carcinoma: preliminary study," Head \& Neck, vol. 35, no. 6, pp. 889-894, 2013.

[82] T. Jinno, S. Kawano, Y. Maruse et al., "Increased expression of interleukin-6 predicts poor response to chemoradiotherapy and unfavorable prognosis in oral squamous cell carcinoma," Oncology Reports, vol. 33, no. 5, pp. 2161-2168, 2015.

[83] E. Schiegnitz, P. W. Kämmerer, H. Schön et al., "Proinflammatory cytokines as serum biomarker in oral carcinoma-a prospective multi-biomarker approach," Journal of Oral Pathology \& Medicine, vol. 47, no. 3, pp. 268-274, 2018.

[84] S. R. Punyani and R. S. Sathawane, "Salivary level of interleukin-8 in oral precancer and oral squamous cell carcinoma," Clinical Oral Investigations, vol. 17, no. 2, pp. 517524, 2013.

[85] S. K. Rao, Z. Pavicevic, Z. du et al., "Pro-inflammatory genes as biomarkers and therapeutic targets in oral squamous cell carcinoma," Journal of Biological Chemistry, vol. 285, no. 42, pp. 32512-32521, 2010.

[86] L. T. Lee, Y. K. Wong, H. Y. Hsiao, Y. W. Wang, M. Y. Chan, and K. W. Chang, "Evaluation of saliva and plasma cytokine biomarkers in patients with oral squamous cell carcinoma," International Journal of Oral \& Maxillofacial Surgery, vol. 47, no. 6, pp. 699-707, 2018.

[87] R. Czerninski, J. R. Basile, T. Kartin-Gabay, A. Laviv, and V. Barak, "Cytokines and tumor markers in potentially malignant disorders and oral squamous cell carcinoma: a pilot study," Oral Diseases, vol. 20, no. 5, pp. 477-481, 2014.

[88] G. Landskron, M. de la Fuente, P. Thuwajit, C. Thuwajit, and M. A. Hermoso, "Chronic inflammation and cytokines in the tumor microenvironment," Journal of Immunology Research, vol. 2014, Article ID 149185, 19 pages, 2014.

[89] E. Vairaktaris, A. Yannopoulos, S. Vassiliou et al., "Strong association of interleukin-4 $(-590 \mathrm{C} / \mathrm{T})$ polymorphism with increased risk for oral squamous cell carcinoma in Europeans," Oral Surgery, Oral Medicine, Oral Pathology, Oral Radiology, and Endodontology, vol. 104, no. 6, pp. 796-802, 2007.

[90] M. Beppu, T. Ikebe, and K. Shirasuna, “The inhibitory effects of immunosuppressive factors, dexamethasone and interleukin- 4 , on NF- $\kappa$ B-mediated protease production by oral cancer," Biochimica et Biophysica Acta (BBA) - Molecular Basis of Disease, vol. 1586, no. 1, pp. 11-22, 2002.

[91] D. A. C. Arantes, N. L. Costa, E. F. Mendonça, T. A. Silva, and A. C. Batista, "Overexpression of immunosuppressive cytokines is associated with poorer clinical stage of oral squamous cell carcinoma," Archives of Oral Biology, vol. 61, pp. 28-35, 2016.

[92] O. Alhamarneh, F. Agada, L. Madden, N. Stafford, and J. Greenman, "Serum IL10 and circulating CD $4^{+} \mathrm{CD} 25^{\text {high }}$ regulatory $\mathrm{T}$ cell numbers as predictors of clinical outcome and survival in patients with head and neck squamous cell carcinoma," Head \& Neck, vol. 33, no. 3, pp. 415-423, 2011.
[93] S. Aziz, S. S. Ahmed, A. Ali et al., "Salivary immunosuppressive cytokines IL-10 and IL-13 are significantly elevated in oral squamous cell carcinoma patients," Cancer Investigation, vol. 33, no. 7, pp. 318-328, 2015.

[94] C. J. Chen, W. W. Sung, T. C. Su et al., "High expression of interleukin 10 might predict poor prognosis in early stage oral squamous cell carcinoma patients," Clinica Chimica Acta, vol. 415, pp. 25-30, 2013.

[95] M. Hamzavi, A. A. Tadbir, G. Rezvani et al., "Tissue expression, serum and salivary levels of IL-10 in patients with head and neck squamous cell carcinoma," Asian Pacific Journal of Cancer Prevention, vol. 14, no. 3, pp. 1681-1685, 2013.

[96] A. S. Gonçalves, D. A. C. Arantes, V. F. Bernardes et al., "Immunosuppressive mediators of oral squamous cell carcinoma in tumour samples and saliva," Human Immunology, vol. 76, no. 1, pp. 52-58, 2015.

[97] M. H. Tsai, W. C. Chen, C. H. Tsai, L. W. Hang, and F. J. Tsai, "Interleukin-4 gene, but not the interleukin-1 beta gene polymorphism, is associated with oral cancer," Journal of Clinical Laboratory Analysis, vol. 19, no. 3, pp. 93-98, 2005.

[98] E. Salehifar and S. J. Hosseinimehr, "The use of cyclooxygenase-2 inhibitors for improvement of efficacy of radiotherapy in cancers," Drug Discovery Today, vol. 21, no. 4, pp. 654-662, 2016.

[99] E. Ricciotti and G. A. FitzGerald, "Prostaglandins and inflammation," Arteriosclerosis, Thrombosis, and Vascular Biology, vol. 31, no. 5, pp. 986-1000, 2011.

[100] B. Yang, L. Jia, Q. Guo, H. Ren, Y. Hu, and T. Xie, "Clinicopathological and prognostic significance of cyclooxygenase2 expression in head and neck cancer: a meta-analysis," Oncotarget, vol. 7, no. 30, pp. 47265-47277, 2016.

[101] A. A. Byatnal, A. Byatnal, S. Sen, V. Guddattu, and M. C. Solomon, "Cyclooxygenase-2 - an imperative prognostic biomarker in oral squamous cell aarcinoma - an immunohistochemical study," Pathology \& Oncology Research, vol. 21, no. 4, pp. 1123-1131, 2015.

[102] H. Li, B. Yang, J. Huang et al., "Cyclooxygenase-2 in tumorassociated macrophages promotes breast cancer cell survival by triggering a positive-feedback loop between macrophages and cancer cells," Oncotarget, vol. 6, no. 30, pp. 2963729650, 2015.

[103] P. N. Patel, A. Thennavan, S. Sen, C. Chandrashekar, and R. Radhakrishnan, "Translational approach utilizing COX2, p53, and MDM2 expressions in malignant transformation of oral submucous fibrosis," Journal of Oral Science, vol. 57, no. 3, pp. 169-176, 2015.

[104] A. Sinanoglu, M. Soluk-Tekkesin, and V. Olgac, "Cyclooxygenase-2 and Ki67 expression in oral leukoplakia: a clinicopathological study," Journal of Oral \& Maxillofacial Research, vol. 6, no. 2, article e3, 2015.

[105] M. Seyedmajidi, S. Shafaee, S. Siadati, M. Khorasani, A. Bijani, and N. Ghasemi, "Cyclo-oxygenase-2 expression in oral squamous cell carcinoma," Journal of Cancer Research and Therapeutics, vol. 10, no. 4, pp. 1024-1029, 2014.

[106] M. Shibata, et al.I. Kodani, M. Osaki et al., "Cyclo-oxygenase-1 and -2 expression in human oral mucosa, dysplasias and squamous cell carcinomas and their pathological significance," Oral Oncology, vol. 41, no. 3, pp. 304-312, 2005.

[107] L. Yadav, N. Puri, V. Rastogi, P. Satpute, R. Ahmad, and G. Kaur, "Matrix metalloproteinases and cancer - roles in 
threat and therapy," Asian Pacific Journal of Cancer Prevention, vol. 15, no. 3, pp. 1085-1091, 2014.

[108] M. Egeblad and Z. Werb, "New functions for the matrix metalloproteinases in cancer progression," Nature Reviews Cancer, vol. 2, no. 3, pp. 161-174, 2002.

[109] M. Neagu, C. Constantin, and C. Tanase, "Immune-related biomarkers for diagnosis/prognosis and therapy monitoring of cutaneous melanoma," Expert Review of Molecular Diagnostics, vol. 10, no. 7, pp. 897-919, 2010.

[110] L. Nissinen and V. M. Kähäri, "Matrix metalloproteinases in inflammation," Biochimica et Biophysica Acta (BBA) General Subjects, vol. 1840, no. 8, pp. 2571-2580, 2014.

[111] H. Hua, M. Li, T. Luo, Y. Yin, and Y. Jiang, "Matrix metalloproteinases in tumorigenesis: an evolving paradigm," Cellular and Molecular Life Sciences, vol. 68, no. 23, pp. 3853-3868, 2011.

[112] I. Solomon, V. M. Voiculescu, C. Caruntu et al., "Neuroendocrine factors and head and neck squamous cell carcinoma: an affair to remember," Disease Markers, vol. 2018, Article ID 9787831, 12 pages, 2018.

[113] R. Roy, J. Yang, and M. A. Moses, "Matrix metalloproteinases as novel biomarker $s$ and potential therapeutic targets in human cancer," Journal of Clinical Oncology, vol. 27, no. 31, pp. 5287-5297, 2009.

[114] P. Y. Chang, Y. B. Kuo, T. L. Wu et al., "Association and prognostic value of serum inflammation markers in patients with leukoplakia and oral cavity cancer," Clinical Chemistry and Laboratory Medicine, vol. 51, no. 6, pp. 1291-1300, 2013.

[115] H. Kadeh, S. Saravani, F. Heydari, M. Keikha, and V. Rigi, "Expression of matrix metalloproteinase-10 at invasive front of squamous cell carcinoma and verrucous carcinoma in the oral cavity," Asian Pacific Journal of Cancer Prevention, vol. 16, no. 15, pp. 6609-6613, 2015.

[116] L. K. Mäkinen, V. Häyry, J. Hagström et al., "Matrix metalloproteinase- 7 and matrix metalloproteinase- 25 in oral tongue squamous cell carcinoma," Head \& Neck, vol. 36, no. 12, pp. 1783-1788, 2014.

[117] A. O. Lawal, A. O. Adisa, B. Kolude, and B. F. Adeyemi, "Immunohistochemical expression of MMP-2 and MMP8 in oral squamous cell carcinoma," Journal of Clinical and Experimental Dentistry, vol. 7, no. 2, pp. e203-e207, 2015.

[118] T. Tanis, Z. B. Cincin, B. Gokcen-Rohlig et al., "The role of components of the extracellular matrix and inflammation on oral squamous cell carcinoma metastasis," Archives of Oral Biology, vol. 59, no. 11, pp. 1155-1163, 2014.

[119] F. T. Liu and G. A. Rabinovich, "Galectins as modulators of tumour progression," Nature Reviews Cancer, vol. 5, no. 1, pp. 29-41, 2005.

[120] V. L. Thijssen, R. Heusschen, J. Caers, and A. W. Griffioen, "Galectin expression in cancer diagnosis and prognosis: a systematic review," Biochimica et Biophysica Acta (BBA) Reviews on Cancer, vol. 1855, no. 2, pp. 235-247, 2015.

[121] M. C. Vladoiu, M. Labrie, and Y. St-Pierre, "Intracellular galectins in cancer cells: potential new targets for therapy (Review)," International Journal of Oncology, vol. 44, no. 4, pp. 1001-1014, 2014.

[122] C. M. Arthur, M. D. Baruffi, R. D. Cummings, and S. R. Stowell, "Evolving mechanistic insights into galectin functions," in Galectins, pp. 1-35, Humana Press, New York, NY, USA, 2015.
[123] Y. Noda, Y. Kondo, M. Sakai, S. Sato, and M. Kishino, "Galectin-1 is a useful marker for detecting neoplastic squamous cells in oral cytology smears," Human Pathology, vol. 52, pp. 101-109, 2016.

[124] Y. Noda, M. Kishino, S. Sato et al., "Galectin-1 expression is associated with tumour immunity and prognosis in gingival squamous cell carcinoma," Journal of Clinical Pathology, vol. 70, no. 2, pp. 126-133, 2017.

[125] S. Aggarwal, S. C. Sharma, and S. N. Das, "Galectin-1 and galectin-3: plausible tumour markers for oral squamous cell carcinoma and suitable targets for screening high-risk population," Clinica Chimica Acta, vol. 442, pp. 13-21, 2015.

[126] J. M. Muniz, C. R. Bibiano Borges, M. Beghini et al., "Galectin-9 as an important marker in the differential diagnosis between oral squamous cell carcinoma, oral leukoplakia and oral lichen planus," Immunobiology, vol. 220, no. 8, pp. 1006-1011, 2015.

[127] J. A. Mesquita, L. M. G. Queiroz, É. J. D. Silveira et al., "Association of immunoexpression of the galectins-3 and -7 with histopathological and clinical parameters in oral squamous cell carcinoma in young patients," European Archives of Oto-Rhino-Laryngology, vol. 273, no. 1, pp. 237-243, 2016.

[128] S. Matsukawa, K.-i. Morita, A. Negishi et al., "Galectin-7 as a potential predictive marker of chemo- and/or radio-therapy resistance in oral squamous cell carcinoma," Cancer Medicine, vol. 3, no. 2, pp. 349-361, 2014.

[129] M. Valko, C. J. Rhodes, J. Moncol, M. Izakovic, and M. Mazur, "Free radicals, metals and antioxidants in oxidative stress-induced cancer," Chemico-Biological Interactions, vol. 160, no. 1, pp. 1-40, 2006.

[130] M. I. Mitran, I. Nicolae, C. D. Ene et al., "Relationship between gamma-glutamyl transpeptidase activity and inflammatory response in lichen planus," Revista de Chimie, vol. 69, no. 3, pp. 739-743, 2018.

[131] S. R. Georgescu, C. D. Ene, M. Tampa, C. Matei, V. Benea, and I. Nicolae, "Oxidative stress-related markers and alopecia areata through latex turbidimetric immunoassay method," Materiale Plastice, vol. 53, no. 3, pp. 522-526, 2016.

[132] N. Khansari, Y. Shakiba, and M. Mahmoudi, "Chronic inflammation and oxidative stress as a major cause of age- related diseases and cancer," Recent Patents on Inflammation \& Allergy Drug Discovery, vol. 3, no. 1, pp. 73-80, 2009.

[133] J. E. Klaunig and L. M. Kamendulis, "The role of oxidative stress in carcinogenesis," Annual Review of Pharmacology and Toxicology, vol. 44, no. 1, pp. 239-267, 2004.

[134] M. Tampa, C. L. Matei, S. A. Popescu et al., "Zinc trisulphonated phthalocyanine used in photodynamic therapy of dysplastic oral keratinocytes," Revista de Chimie, vol. 64, no. 6, pp. 639-645, 2013.

[135] I. Nicolae, M. Tampa, C. Mitran et al., "Gamma-glutamyl transpeptidase alteration as a biomarker of oxidative stress in patients with human papillomavirus lesions following topical treatment with sinecatechins," Farmácia, vol. 65, no. 4, pp. 617-623, 2017.

[136] W. Huo, Z. M. Li, X. Y. Pan, Y. M. Bao, and L. J. An, “Antioxidant enzyme levels in pathogenesis of oral squamous cell carcinoma (OSCC)," Drug Research, vol. 64, no. 11, pp. 629-632, 2014. 
[137] A. Kumar, M. C. Pant, H. S. Singh, and S. Khandelwal, "Determinants of oxidative stress and DNA damage (8OhdG) in squamous cell carcinoma of head and neck," Indian Journal of Cancer, vol. 49, no. 3, pp. 309-315, 2012.

[138] R. Subapriya, R. Kumaraguruparan, C. R. Ramachandran, and S. Nagini, "Oxidant-antioxidant status in patients with oral squamous cell carcinomas at different intraoral sites," Clinical Biochemistry, vol. 35, no. 6, pp. 489-493, 2002.

[139] S. Manoharan, K. Kolanjiappan, K. Suresh, and K. Panjamurthy, "Lipid peroxidation \& antioxidants status in patients with oral squamous cell carcinoma," Indian Journal of Medical Research, vol. 122, no. 6, pp. 529-534, 2005. 


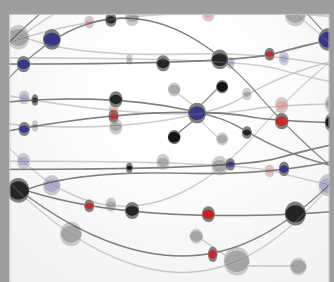

The Scientific World Journal
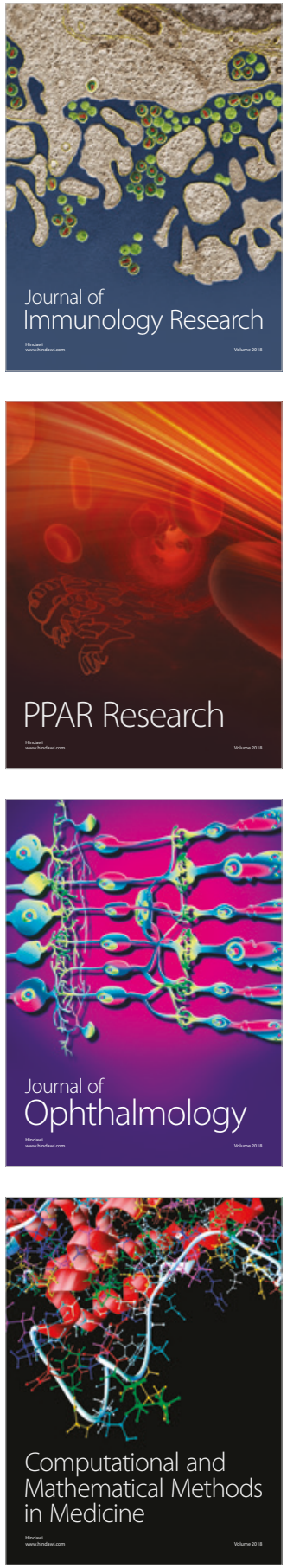

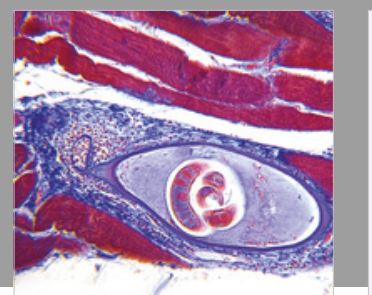

Gastroenterology Research and Practice

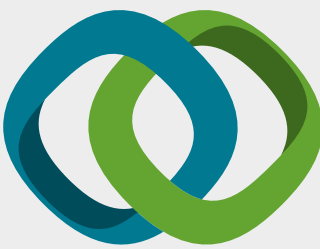

\section{Hindawi}

Submit your manuscripts at

www.hindawi.com
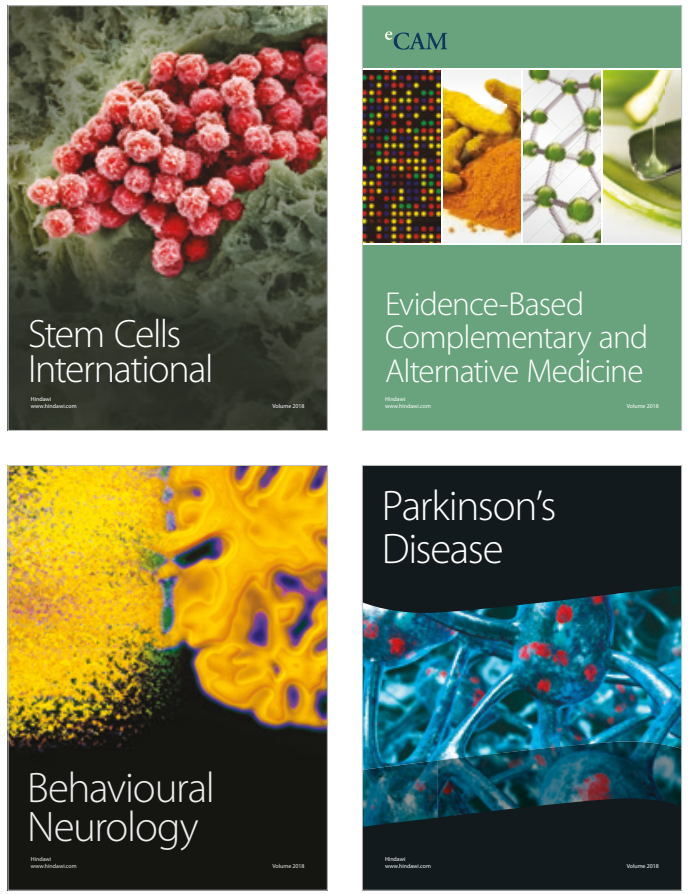

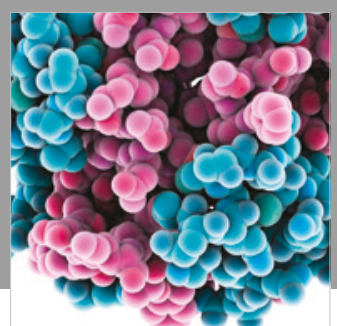

ournal of

Diabetes Research

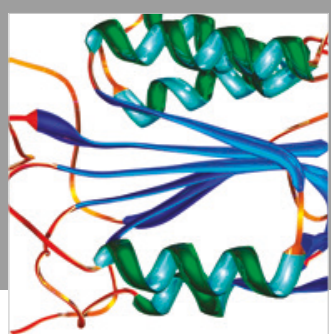

Disease Markers
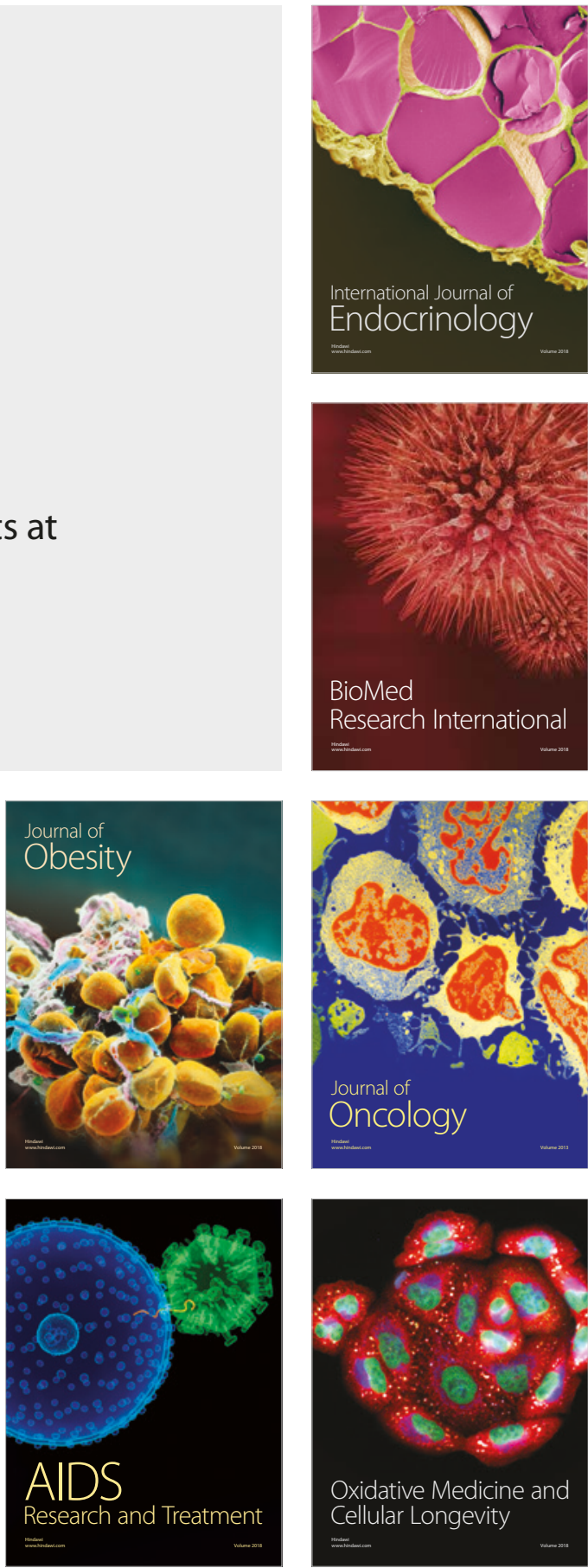